\title{
Immediate versus delayed loading of strategic mini dental implants for the stabilization of partial removable dental prostheses: a patient cluster randomized, parallel-group 3-year trial
}

Torsten Mundt ${ }^{* *}$, Ahmad Al Jaghsi ${ }^{1}$, Bernd Schwahn², Janina Hilgert ${ }^{3}$, Christian Lucas ${ }^{4}$, Reiner Biffar ${ }^{1}$, Christian Schwahn ${ }^{1}$ and Friedhelm Heinemann ${ }^{5}$

\begin{abstract}
Background: Acceptable short-term survival rates (>90 \%) of mini-implants (diameter $<3.0$ mm) are only documented for mandibular overdentures. Sound data for mini-implants as strategic abutments for a better retention of partial removable dental prosthesis (PRDP) are not available.
\end{abstract}

Methods/design: The purpose of this study is to test the hypothesis that immediately loaded mini-implants show more bone loss and less success than strategic mini-implants with delayed loading. In this four-center (one university hospital, three dental practices in Germany), parallel-group, controlled clinical trial, which is cluster randomized on patient level, a total of 80 partially edentulous patients with unfavourable number and distribution of remaining abutment teeth in at least one jaw will receive supplementary min-implants to stabilize their PRDP. The mini-implant are either immediately loaded after implant placement (test group) or delayed after four months (control group). Follow-up of the patients will be performed for 36 months. The primary outcome is the radiographic bone level changes at implants. The secondary outcome is the implant success as a composite variable. Tertiary outcomes include clinical, subjective (quality of life, satisfaction, chewing ability) and dental or technical complications.

Discussion: Strategic implants under an existing PRDP are only documented for standard-diameter implants. Mini-implants could be a minimal invasive and low cost solution for this treatment modality.

Trial registration: The trial is registered at Deutsches Register Klinischer Studien (German register of clinical trials) under DRKS-ID: DRKS00007589 (www.germanctr.de) on January 13 ${ }^{\text {th }}, 2015$.

Keywords: Mini dental implant, Strategic implant, Partial removable dental prosthesis, Supplementary abutment, Implant therapy

\footnotetext{
* Correspondence: mundt@uni-greifswald.de

'Department of Prosthodontics, Greifswald University Hospital,

Gerodontology and Dental Materials, Greifswald, Germany

Full list of author information is available at the end of the article
} 


\section{Background}

In the USA and many European countries there is a decline in edentulism in all age groups. However, the number of partially edentulous patients will increase with a shift in older age groups because the populations of industrial nations are growing older [1, 2]. In Germany, most individuals with reduced dentition demand and receive partial removable dental prostheses (PRDP) that are either retained by double crowns, clasps, ball- or other attachments [3]. The longevity of the remaining teeth and the PRDP depends on the number and localization of the abutments as shown in studies that analysed double crown retained prostheses [4]. According to epidemiological studies, the lower the number of remaining teeth the higher is the incidence of further tooth loss [5]. From the clinical point of view, symmetrical support by the abutment teeth is suggested regardless of the attachment system used [6]. Supplementary implants in strategic positions can ensure a change from a critical prosthetic support (unilateral, linear) to a more favourable support configuration [6-8]. The retention and the stability of PRDPs are better if both quadrants of the jaw show abutments on strategically important areas such as the canine and posterior teeth [9]. This may protect the remaining teeth from overload and reduce possible rotational movements of the RPDP [9]. When an incisor is the terminal abutment in the quadrant, distal implants can reduce the use of retentive elements such as clasps, which provides better aesthetics and periodontal stability [8-10].

For the combination of teeth and implants to support RPDPs, either double crowns [7, 8, 11, 12] or resilient ball-attachments $[6,10,13-19]$ were used on standarddiameter implants $(>3.5 \mathrm{~mm})$.

Standard-diameter implants require a sufficient width of the alveolar ridge $(>5.5 \mathrm{~mm})$. Otherwise, bone augmentation procedures are indicated, which would increase the risk of possible side effects and increase costs and treatment duration [20].

Mini-implants (diameter $<3.0 \mathrm{~mm}$ ) are suggested to be a prosthodontic alternative to standard-diameter implants for solutions in patients with narrow alveolar ridges [20-25]. Additional advantages of mini-implants are the simplified treatment procedures with a flat learning curve, low cost, and the possible flapless surgical procedure which can decrease the post-surgical morbidity [20]. With one exception [26], mini-implants used for the retention of removable prostheses are usually one piece with a retentive ball-attachment. Therefore, noload osseointegration is not achievable. The female matrices (housings with plastic O-rings) can be immediately polymerised into the prostheses after placement of implants with sufficient primary stability. Mini-implants are mainly used for the stabilization of complete dentures. However, long-term survival data for miniimplants are lacking and acceptable short-term survival rates (>90\%) of mini-implants are only documented for mandibular overdentures [20, 27, 28]. The short-term survival rates of immediate loaded mini-implants that are used to stabilize maxillary overdentures were unacceptably low and ranged between $54 \%$ and $85 \%$ [21-23]. The mean radiographic bone loss was $>5 \mathrm{~mm}$ in the first year and therefore higher than in studies on mandibular overdentures with mean bone loss rates between 0.4 and $1.2 \mathrm{~mm}[24,28]$. In a multi-center study [25], the 4-year survival rate of mini-implants for complete denture stabilization was about $95 \%$ without significant differences between the maxilla and mandible. In that study, all MDIs in the receiving jaw were immediately restored by rebasing the dentures with a soft liner when the insertion torque of one MDI was < 35 Ncm. The housings were picked-up after 3-4 months. The mean bone loss was insignificantly higher in the maxilla $(0.8 \mathrm{~mm})$ than in the mandible $(0.5 \mathrm{~mm})$ [29]. In another study on mini-implant supported mandibular overdentures, delayed loading appeared to be preferable to immediate loading regarding implant survival and bone loss [30]. Sound data of mini-implants as strategic abutments for a better retention of PRDPs are not available [20, 23, 27].

\section{Methods/design}

\section{Study aim and design}

The objectives of this study are to show that (1) immediately loaded (with housings)/restored (soft relining) mini-implants show more bone loss and less success than delayed loaded strategic mini-implants, (2) strategic mini-implants improve patients' quality of life, patients' satisfaction, chewing function, retention of the denture, and periodontal health of remaining abutment teeth. However, the improvements in the immediately loaded group will occur faster than in the delayed loaded group.

The protocol of this multi-center randomized parallelgroup clinical trial follows the SPIRIT guidelines [31]. The study was designed according to the Good Clinical Practice guidelines (ICG-GCP) and the principles of the Declaration of Helsinki as revised in 2008.

\section{Study setting and participants}

The Dental School at the Greifswald university hospital and three German private dental practices specializing in dental implantology and prosthodontics participate.

Study participants had to meet the following inclusion criteria:

- At least 2-months-old double crown-retained or clasp-retained PRDP in the maxilla and/or mandible that shows an unfavourable number and distribution 
of remaining abutment teeth in at least one quadrant of the study jaw (see classification Table 1).

- The abutment teeth need to have healthy periodontal conditions (pocket dephts $\leq 4 \mathrm{~mm}$, no bleeding on probing, attachment loss $<$ two third of the root length, mobility grade $\leq 2$ ).

- Vital or endodontically treated abutment teeth with a sealed root filling to the apical region without apical periodontitis.

- No contraindication for implantation, and sufficient bone in the study jaw to place an implant without augmentation procedures

- Written informed consent to participate in the study.

Exclusion criteria for participation were

- Contraindication for implantation without augmentation caused by local bone deficits

- Patients who are satisfied with their PRDP

- Patients who refuse randomizations to one of the study groups
- Poor general health, e.g. Class III-IV according to the classification of the American Society of Anaesthesiology (ASA), severe renal/or liver disease, history of a radiotherapy in the head region, chemotherapy at the time of surgical procedure, non-compensated diabetes mellitus, HIV,

- Ongoing intravenous bisphosphonate therapy

- Mental disorders (anamnestic)

- Drug abuse (anamnestic)

- Active periodontal disease and/or poor oral hygiene (mean plaque index and/or mean sulcus bleeding index $\geq 1$ )

\section{Interventions}

Dentists of the centers with experience in dental implantology for more than ten years, who are familiar with the mini-implant system, perform the surgical and prosthetic treatment. Standard operating procedures were specified in a manual and imparted during the first calibration meeting. The first implant placement in each center was supervised by the treatment coordinator (TC) of the leading center.

Table 1 Classification for strategic mini dental implants on quadrant level

\begin{tabular}{|c|c|c|c|c|}
\hline $\begin{array}{l}\text { Class number } \\
\text { and discription }\end{array}$ & $\begin{array}{c}\mathbf{0} \\
\text { - edentulous }\end{array}$ & $\begin{array}{l}1 \\
1 \\
\text { - only one or } \\
\text { two incisor(s) } \\
\text { present }\end{array}$ & $\begin{array}{l}2 \\
\text { - canine missing } \\
\text { - one lateral tooth } \\
\text { present } \\
\text { - incisor(s) can } \\
\text { be present }\end{array}$ & $\begin{array}{l}\text { - } 3 \\
\text { - } \text { canine missing } \\
\text { two lataral teeth } \\
\text { present } \\
\text { - mandibular incisor(s) } \\
\text { can be present }\end{array}$ \\
\hline $\begin{array}{l}\text { Examples for tooth } \\
\text { distribution in the class }\end{array}$ & & 8 & & \\
\hline $\begin{array}{l}\text { Number of strategic } \\
\text { mini-implants for the } \\
\text { maxilla }\end{array}$ & 3 & 3 & 2 & 1 \\
\hline $\begin{array}{l}\text { Number of strategic } \\
\text { mini-implants for the } \\
\text { mandible }\end{array}$ & 2 & 2 & 1 & 1 \\
\hline $\begin{array}{l}\text { Examples for maxillary } \\
\text { strategic mini-implants }\end{array}$ & $\bullet$ & $\circ \quad$ & 8 & \\
\hline $\begin{array}{l}\text { Examples for } \\
\text { mandibular strategic } \\
\text { mini-implants }\end{array}$ & $\bullet$ & $\bullet$ & - & \\
\hline
\end{tabular}


Mini dental implants (MDI, 3 M ESPE, Seefeld, Germany) with lengths of 10 to $18 \mathrm{~mm}$ and diameters of $1.8 \mathrm{~mm}, 2.1$, and $2.4 \mathrm{~mm}$ are used for the stabilization of PRDPs (Figs. 1 and 2). The total number of abutments per quadrant (with unfavourable distribution and number of remaining abutment teeth) will be increased to at least 3 in the maxilla or at least 2 in the mandible by the insertion of strategic MDIs (Table 1). The posterior MDI should be placed at the most posterior area of the dental arch according to the local bone volume. In the mandible, the MDIs should be located always mesial of the mental foramen. Whenever possible, the region of the canine should be occupied by an MDI (alternatively the regions of the first premolar and the lateral incisor should show abutments after intervention). If the insertion torque of one implant is $<15 \mathrm{Ncm}$ due to poor bone quality the patient must be excluded from the study. Recesses for female matrices (housings) were prepared in the existing PRDP. Thereafter, a sealed envelope with the randomization detail was opened and the patient was allocated either to test group A (immediate loading/ restoration) or control group B (delayed loading).

Test group A (immediate loading/restoration):

If the insertion torque of all MDIs in the study jaw was $\geq 35 \mathrm{Ncm}$ implants were immediately loaded. The female housings were seated on the ball attachments and picked-up using self-cured acrylic resin (Secure hard pick-up kit, 3 M ESPE, Seefeld, Germany). If the insertion torque of one MDI in the study jaw is $<35 \mathrm{Ncm}$ all MDIs of this jaw were immediately restored by relining the dentures with a soft material (Secure soft reline kit, 3 M ESPE, Seefeld, Germany) embracing the ball heads. After 4 months, the soft base were substituted with the housings and acrylic resin (Fig. 3).

Control group B (delayed loading):

The recesses for the female housings in the PRDP remained empty for 4 months. Thereafter, the housings were seated on the ball attachments and picked-up using

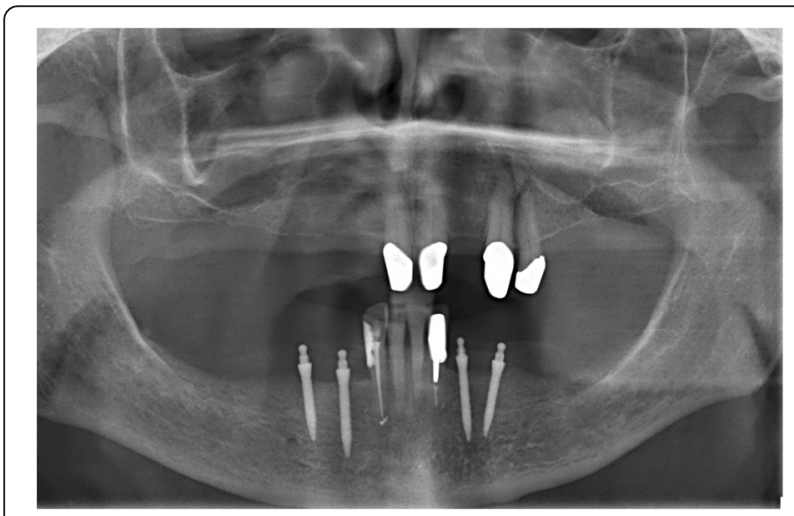

Fig. 1 Pantomographic image of 4 mandibular strategic mini dental implants

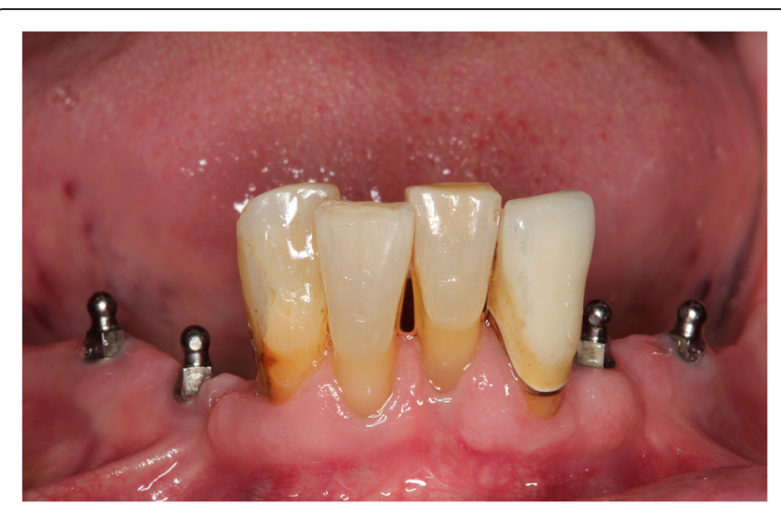

Fig. 2 Mini dental implants presented in Fig. 1 after two weeks

self-cured acrylic resin (Secure hard pick-up kit, $3 \mathrm{M}$ ESPE, Seefeld, Germany). In the case of mucosal hyperplasia around the implant before to the fourth months, the recesses should be relined earlier using the soft material.

During the study period and thereafter the participants will be treated by the dentists of the study sites according to their dental healthcare needs. Treatments could arise from study-related events, e.g. implant or tooth loss, prosthesis fractures or study-independent events, e. g. in the opposite jaw. Treatments before study closure will be considered as outcomes.

\section{Outcomes}

Crestal bone levels as the primary outcome of this trial will be determined at the 1- and 3-year followups by panoramic radiographs and compared with the level immediately after implant placement (Fig. 4). Implant success is the secondary outcome according to the modified criteria by Albrektsson et al. [32]: (a) implant in situ; (b) clinical immobility of the implant; (c) no evidence of peri-implant radiolucency; (d) bone loss less than $1.5 \mathrm{~mm}$ for the first year and less than

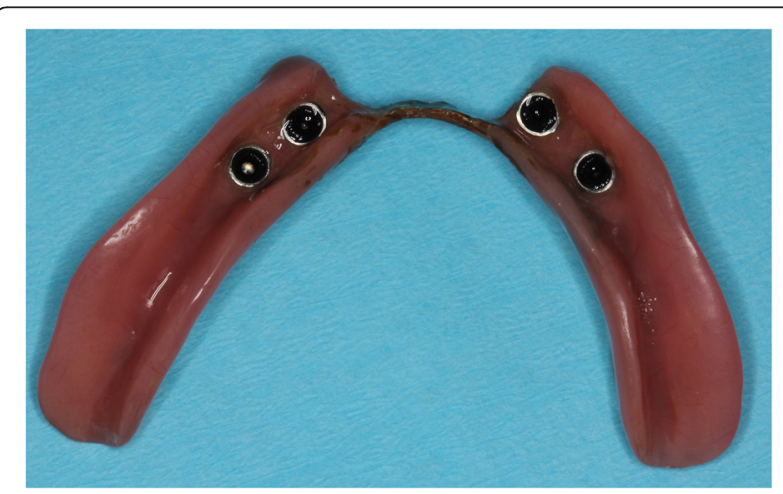

Fig. 3 Housings for the implants presented in Fig. 2 were picked up after 4 months 


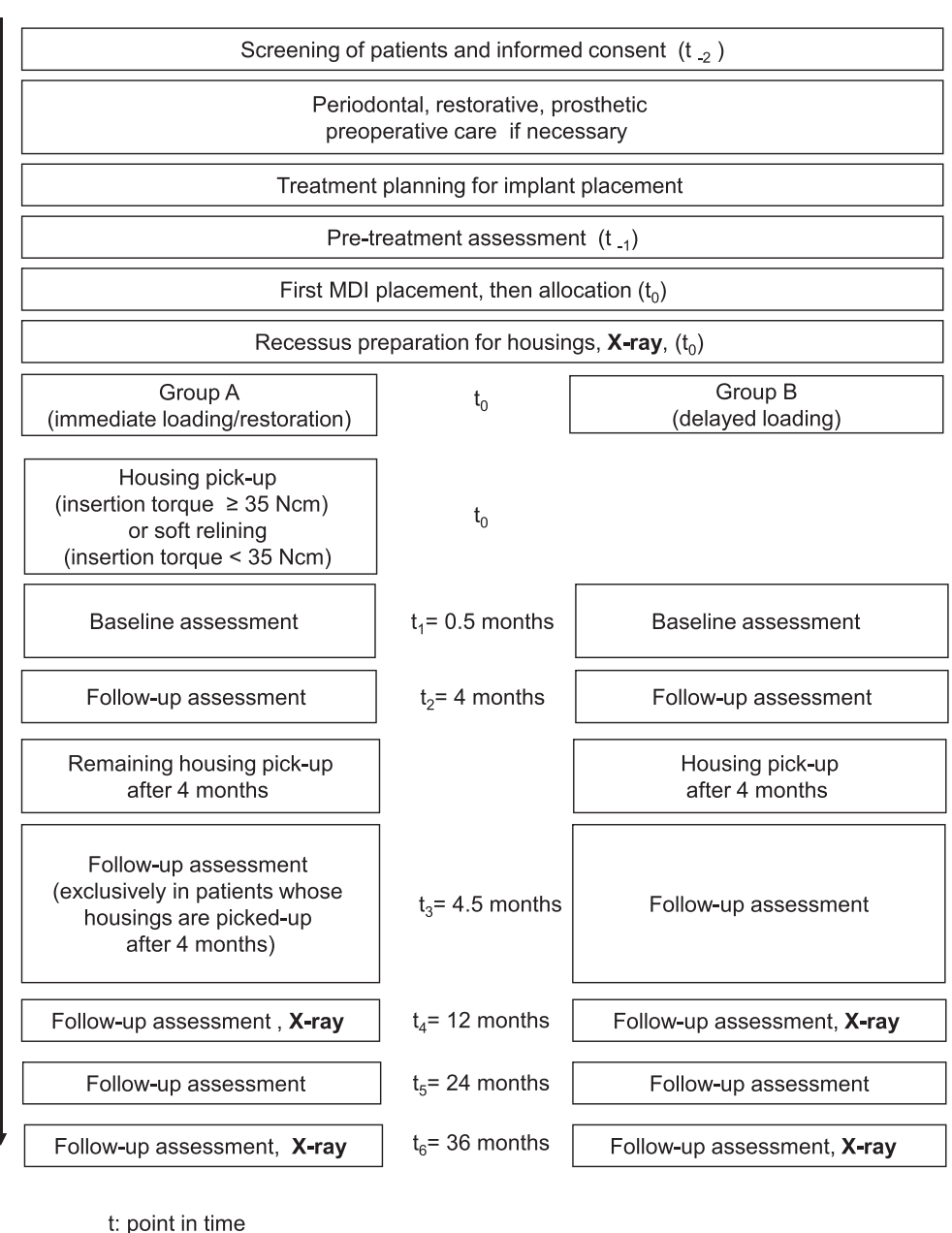

Fig. 4 Organization chart of the trial

$0.2 \mathrm{~mm}$ annually after the first year of service; (e) no persistent pain, discomfort or infection. The hypothesis is tested whether immediate loaded MDIs of the test group show more bone loss and less success than the MDIs of the control group.

Tertiary outcomes are

1. Periodontal and peri-implant conditions (probing depths, bleeding on probing (BOP), modified plaque index, modified sulcus bleeding index (mod. SBI), tooth and implant mobility measured by Periotest and Osstell)

2. Oral health related quality of life (measure: short German version of the oral health impact profile (OHIP-G14) [33] and Patient's satisfaction with the PRDP (Likert scale: totally satisfied - not at all satisfied) [34]

3. Food frequency and avoidance questionnaire will be completed by the patients to evaluate the nutrition of the patients [35]
4. Chewing efficiency will be quantified with colourmixing ability test using a two coloured chewing gum (optoelectronical.evaluation of the ratio of unmixed colour pixels to the total pixel number in a fixed size template) [36]

5. Dental and prosthetic complications: tooth loss, caries, endodontic treatment, implant- or tooth fracture, prosthesis fracture, loss of retention, housing detachments, loss of O-rings.

We hypothesized that after the placement of MDIs there will be significant improvements only in group A and not in group B at the baseline and at the 4- month follow-up examination. After the pick-up of the housings in group B there will be also significant improvements for patients of this group.

Examinations for all secondary outcomes are scheduled before implant placement (pre-treatment, exclusively outcomes No.1-4), 14 days after implant placement (baseline) and 4, 12, 24 and 36 months after implant placement 
(Fig. 4). In addition, patients whose housings are pickedup after 4 months will be examined 14 days after the pickup. A trained examiner of the leading treatment center not involved in the treatment of participants will perform all examinations. Additionally, a second examiner will survey the bone levels at implants on the radiographs.

\section{Stopping criteria}

A participant will be excluded from the trial if (a) the insertion torque of one implant is <15 Ncm; (b) the patient shows intolerance/allergy to titanium; (c) the occurrence of any serious adverse events related to the implantation; (d) degradation in the health status that compromises the participation in the trial; (e) failure to comply with trial requirements; (f) the patient withdraws her/his consent. The examiner and the dentists of the treatment centers are committed to report the principal investigator on the occurrence of events promptly.

The study will be terminated if (a) more than $20 \%$ of the implants fail in any group after implant placement;

(b) recruitment will not reach $80 \%$ of the estimated number of patients during the first year; (c) the response after the first year is $<80 \%$ of included participants.

The criteria will be checked every six months after the inclusion of the first patient. Premature termination of the trial should be decided by principal investigator in agreement with the sponsor.

\section{Sample size}

The power calculation is based on bone loss data in a randomized study on mandibular overdentures [37] similar to the present study. Delayed loaded regulardiameter implants of 15 patients showed bone loss of $0.51 \pm 0.39 \mathrm{~mm}$ after one year and of $0,62 \pm 0.44 \mathrm{~mm}$ after 3 years. Immediate loaded implants of 15 patients showed bone loss of $0.91 \pm 0.63 \mathrm{~mm}$ after 1 year and $0.98 \pm 0.64 \mathrm{~mm}$ after 3 years. A sample size of 26 in each group will have $80 \%$ power to detect a difference in means of 0.4 (the difference between a group 1 mean of 0.9 and a group 2 mean of 0.5 ) assuming that the common standard deviation is 0.5 using a two group t-test with a 0.05 two-sided significance level. Considering response rate of $75 \%$, a total of 80 patients (40 per group) should be allocated to the trial.

\section{Randomization and blinding}

The randomization was performed centrally by the trial statistician based on a sequence of computer-generated numbers with a 1:1 allocation ratio stratified by jaw (maxilla, mandible) and study center.

Due to the apparent treatment differences, it is not possible to blind the dentists, clinical investigator, and/ or the participating patient. However, the two examiners of the radiographs and the statistician will be blinded.

\section{Data management}

The data of the paper case report forms will be entered in the electronical spreadsheet by assistants of the leading study site. Non-numeric data will be coded not only for statistical analyses but also to identify missing or erroneous values by range checks. The cases are pseudonymized (continuously counted according to a single main list). Each participating center got an identification number (ID-CENTER). Subjects included in the cohort got a pseudonym (ID-PROBAND) by the participating center. The centers are the keyholders for the patients' personal data. The list of pseudonyms and patients' ID will be listed in a special file. Only the head of the department in the dental school (keyholder) could open the pseudonyms. The principal investigator will have access to the cleaned dataset. Other members of the research group will be given access to data for analyses and publication by request.

Participant forms will be stored in locked office cabinets. The case report forms will be archived for 15 years after study closure. A member of our board of the community medicine research net with expertise in statistical methodology will guarantee the abidance of randomization and quality assurance at the data acquisition and data base. Every 12 months the member and the sponsor will forward interim reports without any analyses.

\section{Statistical methods}

Because of the statistical power, we choose the continuous variable bone level to be the primary outcome measure. We differentiate confirmatory and exploratory analyses. Confirmatory analysis is related to differences between groups whereas exploratory analysis is related to the rate of change between groups (interaction between time and group), which yields low power test herein. However, we present the joint test of the factor group and the interaction between time and group. The explanations of the variables are outlined in Table 2 .

\section{Primary outcome: bone level}

Because jaw was used for randomization, we extend Gilthorpe's mixed model by inserting jaw to levels for patient, tooth, and site [38] and adjust for model complexity by using the Kenward-Roger correction [39]. To ensure hierarchical levels, tooth positions within each jaw are coded from 1 to 16 instead of from 1 to 32 on patient level. The first adjustment set consists of risk factors of periodontal disease including age, gender, and smoking [40]; and design variables including centre, jaw [41], jaw classification, and time. Because $\mathrm{X}$-ray at $\mathrm{t}_{0}$ is assessed before differentiating treatment in groups, it is a baseline measurement which can additionally be used to increase efficiency [42]. Note also the discussion on pages 158-160 in Harrell's 
Table 2 Variables, measures, hypotheses, and methods of analysis

\begin{tabular}{|c|c|c|c|c|c|c|}
\hline Variable & Measure, parameterization & $\begin{array}{l}\text { Variable name } \\
\text { for syntax }\end{array}$ & Level & Hypothesis & Points in time & $\begin{array}{l}\text { Methods of analysis: Stata } \\
\text { command (version 14) }\end{array}$ \\
\hline \multicolumn{7}{|l|}{ 1. Primary outcome } \\
\hline a) Bone level & $\begin{array}{l}\text { Radiographic bone levels around } \\
\text { implants (mesial, distal, mm, } \\
\text { continuous) }\end{array}$ & Bone level & Implant & $\begin{array}{l}\text { Group A will show more } \\
\text { bone loss than group B }\end{array}$ & $\left(t_{0}\right), t_{4}, t_{6}$ & $\begin{array}{l}\text { Mixed model for continuous } \\
\text { responses: mixed }\end{array}$ \\
\hline $\begin{array}{l}\text { 2. Secondary outcome: } \\
\text { Implant success }\end{array}$ & $\begin{array}{l}\text { Modified criteria of Albrektsson } \\
\text { (binary): composite variable on } \\
\text { implant level }\end{array}$ & Success & Implant & $\begin{array}{l}\text { Group A will show less } \\
\text { success than group B }\end{array}$ & $t_{4}, t_{6}$ & $\begin{array}{l}\text { Mixed model for binary } \\
\text { responses: melogit }\end{array}$ \\
\hline \multirow[t]{2}{*}{ a) Related to infection } & $\begin{array}{l}\text { Modified sulcus bleeding index } \\
\text { (0-3 on } 2 \text { sites per implant) }\end{array}$ & $\mathrm{SBI}$ & Implant & & $\mathrm{t}_{1}, \mathrm{t}_{2}, \mathrm{t}_{3}, \mathrm{t}_{4}, \mathrm{t}_{5}, \mathrm{t}_{6}$ & $\begin{array}{l}\text { Mixed model for ordinal } \\
\text { responses: meologit }\end{array}$ \\
\hline & $\begin{array}{l}\text { Bleeding on probing (binary on } \\
4 \text { sites per implant) }\end{array}$ & $\mathrm{BOP}$ & Implant & & $t_{1}, t_{2}, t_{3}, t_{4}, t_{5}, t_{6}$ & $\begin{array}{l}\text { Mixed model for binary } \\
\text { responses: melogit }\end{array}$ \\
\hline b) Clinical immobility & $\begin{array}{l}\text { Clinical immobility of the implant } \\
\text { (binary) }\end{array}$ & Mobility & Implant & & $t_{1}, t_{2}, t_{3}, t_{4}, t_{5}, t_{6}$ & $\begin{array}{l}\text { Mixed model for binary } \\
\text { responses: melogit }\end{array}$ \\
\hline c) Pain & $\begin{array}{l}\text { Persistent pain or discomfort } \\
\text { (binary) }\end{array}$ & Pain & Implant & & $t_{1}, t_{2}, t_{3}, t_{4}, t_{5}, t_{6}$ & $\begin{array}{l}\text { Mixed model for binary } \\
\text { responses: melogit }\end{array}$ \\
\hline d) Radiolucency & $\begin{array}{l}\text { Evidence of peri-implant } \\
\text { radiolucency (binary) }\end{array}$ & XLucency & Implant & & $t_{4}, t_{6}$ & $\begin{array}{l}\text { Mixed model for binary } \\
\text { responses: melogit }\end{array}$ \\
\hline e) Survival & Implant in situ (binary) & ImplantLoss & Implant & & Continuous time & Kaplan-Meier \\
\hline \multicolumn{7}{|l|}{ 3. Tertiary outcome } \\
\hline \multirow[t]{5}{*}{$\begin{array}{l}\text { a) Periodontal and periimplant } \\
\text { conditions }\end{array}$} & $\begin{array}{l}\text { Probing depths (mm, continuous } \\
\text { on } 4 \text { sites per implant) }\end{array}$ & ProbingDepth & Implant & $\begin{array}{l}\text { Group A will show higher } \\
\text { values than group B }\end{array}$ & $\mathrm{t}_{1}, \mathrm{t}_{2}, \mathrm{t}_{3}, \mathrm{t}_{4}, \mathrm{t}_{5}, \mathrm{t}_{6}$ & $\begin{array}{l}\text { Mixed model for continuous } \\
\text { responses: mixed }\end{array}$ \\
\hline & $\begin{array}{l}\text { Probing depths (mm, continuous } \\
\text { on } 4 \text { sites per tooth) }\end{array}$ & ProbingDepth & Tooth & $\begin{array}{l}\text { Overall improvement at } \\
\text { teeth, } \\
\text { improvement occurred faster } \\
\text { in group A than in group B }\end{array}$ & $\mathrm{t}_{1}, \mathrm{t}_{2}, \mathrm{t}_{3}, \mathrm{t}_{4}, \mathrm{t}_{5}, \mathrm{t}_{6}$ & $\begin{array}{l}\text { Mixed model for continuous } \\
\text { responses: mixed }\end{array}$ \\
\hline & $\begin{array}{l}\text { Osstell (0-100, continuous on } \\
\text { implant level) }\end{array}$ & Osstell & Implant & $\begin{array}{l}\text { Group A will show lower } \\
\text { values than group B until the } \\
\text { fourth month, thereafter } \\
\text { equalization between A } \\
\text { and B }\end{array}$ & $t_{1}, t_{2}, t_{3}, t_{4}, t_{5}, t_{6}$ & $\begin{array}{l}\text { Mixed model for continuous } \\
\text { responses: mixed }\end{array}$ \\
\hline & $\begin{array}{l}\text { Periotest }(-8.0-+50.0 \text {, continuous } \\
\text { on tooth level) }\end{array}$ & Periotest & Tooth & $\begin{array}{l}\text { Overall improvement at } \\
\text { teeth, improvement occurred } \\
\text { faster in group A than in } \\
\text { group B }\end{array}$ & $t_{1}, t_{2}, t_{3}, t_{4}, t_{5}, t_{6}$ & $\begin{array}{l}\text { Mixed model for continuous } \\
\text { responses: mixed }\end{array}$ \\
\hline & $\begin{array}{l}\text { Periotest }(-8.0-+50.0 \text {, continuous } \\
\text { on implant level) }\end{array}$ & Periotest & Implant & $\begin{array}{l}\text { Group } A \text { will show higher } \\
\text { values than group } B \text { until the } \\
\text { fourth month, thereafter } \\
\text { equalization between } A \text { and } B\end{array}$ & $t_{1}, t_{2}, t_{3}, t_{4}, t_{5}, t_{6}$ & $\begin{array}{l}\text { Mixed model for continuous } \\
\text { responses: mixed }\end{array}$ \\
\hline
\end{tabular}


Table 2 Variables, measures, hypotheses, and methods of analysis (Continued)

\begin{tabular}{|c|c|c|c|c|c|c|}
\hline $\begin{array}{l}\text { b) Oral health related quality } \\
\text { of life }\end{array}$ & $\begin{array}{l}\text { OHIP-G14 questionnnaire (0-56, } \\
\text { continuous) }\end{array}$ & OHIP & Patient & $\begin{array}{l}\text { Overall improvement, } \\
\text { improvement occurred faster } \\
\text { in group A than in group B }\end{array}$ & $t_{1}, t_{2}, t_{3}, t_{4}, t_{5}, t_{6}$ & $\begin{array}{l}\text { Mixed model for ordinal } \\
\text { responses: meologit }\end{array}$ \\
\hline $\begin{array}{l}\text { c) Patient's satisfaction with } \\
\text { the PRDP }\end{array}$ & $\begin{array}{l}\text { Questionnnaire } 8 \text { items (Five-point } \\
\text { Likert-scale, 8-40 continuous) }\end{array}$ & Satisfaction & Patient & $\begin{array}{l}\text { Overall improvement, } \\
\text { improvement occurred faster } \\
\text { in group A than in group B }\end{array}$ & $t_{1}, t_{2}, t_{3}, t_{4}, t_{5}, t_{6}$ & $\begin{array}{l}\text { Mixed model for ordinal } \\
\text { responses: meologit }\end{array}$ \\
\hline \multirow[t]{2}{*}{ d) Nutrition of the patients } & Food frequency questionnaire (1-7) & FFQ & Patient & $\begin{array}{l}\text { Overall improvement, } \\
\text { improvement occurred faster } \\
\text { in group A than in group B }\end{array}$ & $\mathrm{t}_{1}, \mathrm{t}_{2}, \mathrm{t}_{3}, \mathrm{t}_{4}, \mathrm{t}_{5}, \mathrm{t}_{6}$ & $\begin{array}{l}\text { Mixed model for ordinal } \\
\text { responses: meologit }\end{array}$ \\
\hline & $\begin{array}{l}\text { Food avoidance questionnaire } \\
\text { (binary) }\end{array}$ & $\mathrm{FAQ}$ & Patient & $\begin{array}{l}\text { Overall improvement, } \\
\text { improvement occurred faster } \\
\text { in group A than in group B }\end{array}$ & $t_{1}, t_{2}, t_{3}, t_{4}, t_{5}, t_{6}$ & $\begin{array}{l}\text { Mixed model for binary } \\
\text { responses: melogit }\end{array}$ \\
\hline e) Chewing efficiency & $\begin{array}{l}\text { Colour-mixing ability test with two } \\
\text { coloured chewing gum (continuous) }\end{array}$ & Chewing & Patient & $\begin{array}{l}\text { Overall improvement, } \\
\text { improvement occurred faster } \\
\text { in group A than in group B }\end{array}$ & $t_{1}, t_{2}, t_{3}, t_{4}, t_{5}, t_{6}$ & $\begin{array}{l}\text { Mixed model for ordinal } \\
\text { responses: meologit }\end{array}$ \\
\hline \multicolumn{7}{|l|}{ 4. Exposure } \\
\hline Group & 2 categories & & Jaw & & $t_{0}$ & \\
\hline \multicolumn{7}{|l|}{ 5. Time variables } \\
\hline TimePoint & 0-6 for outcomes & & & & $0-6$ for $t_{0}-t_{6}$ & \\
\hline Week & Time [weeks] & & Patient & & Week & \\
\hline SqrtWeek & Square root of week & & Patient & & Root of week & \\
\hline Time & & & Patient & & Continuous & \\
\hline \multicolumn{7}{|l|}{ 6. Confounder } \\
\hline Age & $\begin{array}{l}\text { Restricted cubic splines with } 3 \text { knots } \\
\text { ( } 2 \text { coefficients) }\end{array}$ & Age & Patient & & $\mathrm{t}_{-1}$ & \\
\hline Gender & 2 categories (men; women) & Gender & Patient & & $\mathrm{t}_{-1}$ & \\
\hline Center & 4 categories & Center & Patient & & $\mathrm{t}_{-1}$ & \\
\hline Jaw class & 4 categories & JawClass & Jaw & & $\mathrm{t}_{-1}$ & \\
\hline Jaw & 2 categories (upper; lower) & Jaw & Jaw & & $\mathrm{t}_{-1}$ & \\
\hline Tooth & 1-16 within jaw & Tooth & Tooth & & $\mathrm{t}_{-1}$ & \\
\hline Site & Up to 4 sites & Site & Site & & & \\
\hline Smoking & 3 categories (never; ex; current) & Smoking & Patient & & & \\
\hline School education & 3 categories $(<10,10,>10$ years $)$ & Education & Patient & & $\mathrm{t}_{-1}$ & \\
\hline Probing depth & $\begin{array}{l}\text { Restricted cubic splines with } 3 \text { knots } \\
\text { ( } 2 \text { coefficients) }\end{array}$ & ProbingDepth0 & Tooth & & $\mathrm{t}_{-1}$ & \\
\hline
\end{tabular}


Table 2 Variables, measures, hypotheses, and methods of analysis (Continued)

\begin{tabular}{|c|c|c|c|c|c|}
\hline Bone level & Before treatment in groups & BoneLevel0 & & & $t_{0}$ \\
\hline Periotest & $\begin{array}{l}\text { Restricted cubic splines with } 3 \text { knots } \\
\text { ( } 2 \text { coefficients) }\end{array}$ & Periotest0 & Tooth & & $\mathrm{t}_{-1}$ \\
\hline $\begin{array}{l}\text { OHIP-G14 questionnnaire } \\
\text { (0-56, continuous) }\end{array}$ & $\begin{array}{l}\text { Restricted cubic splines with } 3 \text { knots } \\
\text { ( } 2 \text { coefficients) }\end{array}$ & OHIPO & Patient & & $\mathrm{t}_{-1}$ \\
\hline $\begin{array}{l}\text { Questionnnaire } 8 \text { items } \\
\text { (Five-point Likert-scale, } \\
8-40 \text { continuous) }\end{array}$ & Linear term only & Satisfaction0 & Patient & & $\mathrm{t}_{-1}$ \\
\hline $\begin{array}{l}\text { Food frequency questionnaire } \\
(1-7)\end{array}$ & Linear term only & FFQO & Patient & & $\mathrm{t}_{-1}$ \\
\hline $\begin{array}{l}\text { Food avoidance questionnaire } \\
\text { (binary) }\end{array}$ & & FAQ0 & Patient & & $\mathrm{t}_{-1}$ \\
\hline $\begin{array}{l}\text { colour-mixing ability test with } \\
\text { two coloured chewing gum } \\
\text { (continuous) }\end{array}$ & Linear term only & Chewing0 & Patient & & $\mathrm{t}_{-1}$ \\
\hline \multicolumn{6}{|l|}{ 7. Subgroup analysis } \\
\hline Jaw class 0 vs $1-3$ & Secondary outcomes & JawClass & & $\begin{array}{l}\text { Improvement in group } A \text { is } \\
\text { better than in group } B\end{array}$ & $\mathrm{t}_{-1}$ \\
\hline \multicolumn{6}{|l|}{ 8. Additional analysis } \\
\hline Maxilla vs. mandible & All outcomes & & & $\begin{array}{l}\text { Maxilla will show less success } \\
\text { and more bone loss than } \\
\text { mandible; Implant stability } \\
\text { (Periotest, Osstell) is lower in } \\
\text { the maxilla than in the } \\
\text { mandible; no differences in } \\
\text { the improvement of other } \\
\text { secondary outcomes }\end{array}$ & $\mathrm{t}_{-1}$ \\
\hline
\end{tabular}


textbook [43]. The syntax of the basic confirmatory model with the highest statistical power for the factor group is (Stata's version 14):

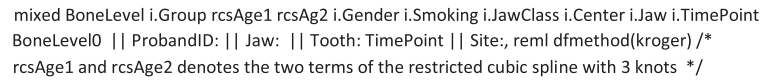

Here, only the time points $t_{4}$ and $t_{6}$ are used as dependent variable (Table 2). To interpret changes after 12 and 36 months in exploratory analyses, we include $t_{0}$ as dependent variable:

mixed BoneLevel i.Group rcsAge1 rcsAg2 i.Gender i.Smoking i.JawClass i.Center i.Jaw i.TimePoint i.Group\#i.TimePoint || ProbandID: || Jaw: || Tooth: TimePoint || Site:, rem| dfmethod(kroger)

In sensitivity analyses, we allow for continuous time instead of points in time, for correlated random effects, or for random effects of other than tooth level and suspend the Kenward-Roger correction. In the second adjustment set, jaw classification is replaced by patient's mean probing depth before randomization; in the third and fourth set, school education will be added to the first and second set, respectively.

\section{Secondary outcomes}

To avoid false positive conclusions, we state a priority ordering in advance [44] based on information on scale (continuous/ordinal/binary), number of time points, level (site/tooth/jaw/patient), and expected number of events (see Table 2).

For six time points, we allow for nonlinear change. The nonlinear change is modelled by taking the square root of time [45] because we expect a higher rate of change in the first weeks. The confirmatory and the exploratory SBI model:

meologit SBI i.Group rcsAge1 rcsAg2 i.Gender i.Smoking i.JawClass i.Center i.Jaw SqrtWeek || ProbandID: || Jaw: || Tooth: SqrtWeek || Site:

meologit SBI i.Group rcsAge1 rcsAg2 i.Gender i.Smoking i.JawClass i.Center i.Jaw SqrtWeek i.group\#c.SqrtWeek || ProbandID: || Jaw: || Tooth: SqrtWeek || Site:

\section{Tertiary outcomes}

See Table 2 for priority ordering. We allow for nonlinear change as described above. If possible we adjust for values before treatment $[40,43]$. The confirmatory and the exploratory model of periotest for teeth:

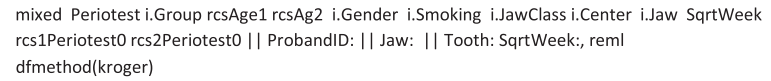

For tertiary outcomes other than periodontal or periimplant conditions, we expect differences between groups before housing in group B (time points $t_{1}$ and $t_{2}$ ) but no differences after that (time points $t_{4}-t_{6}$ ). Thus, we present only confirmatory analyses. The model for food frequency questionnaire at time points $t_{1}$ and $t_{2}$ :

meologit FFQ i.Group rcsAge1 rcsAg2 i.Gender i.Smoking i.JawClass i.Center i.Jaw i.TimePoint FFQ0

if inlist(TimePoint,1,2) || ProbandID: TimePoint

\section{Per protocol set}

We define the per-protocol by the following criteria: only one study jaw per patient; minimum number of implants as indicated in Table 1; no poor general health, no bisphosphonate therapy, no mental disorder, and no drug abuse during follow-ups; X-ray examination after 36 months is available.

\section{Evaluation of safety and tolerability}

Because the sample size on patient level is low, we do not analyse differences between groups but describe vital signs and clinical adverse events with type, time, and severity.

\section{Additional notes}

We do not impute missing data for two reasons. First, we choose mixed models, which are robust to missing data at random [45]; second, an imputation on four levels for this small sample of about 80 patients can hardly be justified [46]. For model checking and sensitivity analysis we use a variety of methods [45, 47]. For subgroup analysis of jaw classification, the two-sided alpha level will be reduced from 0.05 to 0.025 .

An interim analysis will not be done. A statistician (CS) blinded to the study groups will perform the calculations by using up-to-date versions of STATA (StataCorp LP, College Station, Texas, USA) and $\mathrm{R}$ for windows, Version 2.12.2 (R Foundation for Statistical Computing, Vienna, Austria).

\section{Recruitment}

Suitable patients were recruited via personal information during standard recall in two steps. Patients with a suitable dental status were asked whether they were satisfied with their PRDP. After signed informed consent, patients that are unsatisfied with their RPDP were screened according to the inclusion and exclusion criteria. Patient with treatment need, i.e. technically inacceptable RPDP, periodontitis, caries, but who otherwise met the inclusion criteria received firstly an adequate dental and/or prosthodontic treatment, Thereafter, they were re-examined.

All patients were evaluated by the calibrated examiner. Patients meeting the dental, medical, and prosthodontic inclusion criteria, were radiographically examined using panoramic X-ray with a reference marker (titanium tube, steel pin, steel ball) to determine whether the residual bone of the jaw meets the inclusion criterion: to place the MDIs without augmentation procedures. In order to 
achieve comparable treatment plans, the TC assessed the $\mathrm{X}$-rays and pseudonymized documents of each patient to check and, if necessary, to correct the original treatment plan of all centres. If all inclusion criteria were met, patients were included in the study. In addition to the pretreatment examination, the baseline characteristics (age, gender, medical history, smoking habits, oral health behaviour, school education, household income) of the study participants were assessed by a questionnaire. The schedule of recruitment was 17 months (First Patient in 01.11.2013, last Patient in: 31.03.2015).

\section{Audits}

Audits will be conducted to ensure data validity and reliability. The sponsor may assign independent persons (auditors) otherwise not involved in trial conduct to perform audits at the study centers. The auditors are granted permission to access study-related documents (i.e. protocol, participant files, study-related correspondence). Auditors are supposed to comply with data protection.

\section{Publication}

Analyses, presentations and publications will include the data of all study sites and not from one center alone. Results of prespecified outcome parameters will be published and released to the general medical community and patients regardless of the magnitude or effect direction of interventions.

The lead author, the principal investigator, the examiner, the statistician and at least one author per center will be listed as authors in presentations and publications. Additional professionals can be listed in the acknowledgement section. Professional medical writers will be not deployed.

\section{Discussion}

This randomized multi-center trial was initiated by the researchers to compare the immediate loading/restoration with delayed loading of the implants and to evaluate the suitability of MDIs as supplementary abutment for the stabilization of PRDPs regardless of the loading time.

Some limitations of this study merit consideration. Although all treating dentists of the four centers have been using dental implants for more than 10 years and are familiar with the MDI system, entrenched approaches could result in different outcomes despite of the treatment manual and calibration session. Therefore, the first interventions were supervised by the treatment coordinator of the leading center to avoid treatment differences effectively. Nevertheless, multivariate analyses will be adjusted by the study centers. The study jaws showed different distributions of remaining teeth and different types of prostheses. Therefore, the classification was developed and subgroup analyses are planned to consider the various starting positions. Because patients who are satisfied with their PRDP were excluded, this criterion might bias patients to positive answers following MDI placement. However, the desire for dental implants is very weak among satisfied patients. Therefore, overtreatment should be avoided.

Nevertheless, this is the first study to evaluate the effectiveness of MDI for the stabilization of RPDP. The therapy approaches are standardized as far as possible. The examinations are performed by a dentist who is not involved in the treatment of the patients.

The idea of this clinical trial was to compare two different loading protocols and not two different treatment alternatives, e.g., the placement of standard-diameter implants versus mini-implants or no implant placement versus mini-implants. No implant placement would imply ethical conflicts and response problems after randomization. Standard-diameter implants require sufficient bone volume. Therefore, in narrow alveolar ridges, augmentative procedures would be necessary.

Before recruitment of study participants, the minimum number must be estimated to detect a statistically significant difference between the groups as in the present study. The sample size calculation requires assumptions that are typically cannot really be tested until the data have been collected. Sample size calculations are thus inherently hypothetical [48]. The number of additional subjects to consider dropouts over the study period is based on the experience of researchers [49]. The sample size for this trial required a multi-center design. The estimated loss to follow-up rate of $25 \%$ is rather conservative and should also consider stopping criteria such as a low insertion torque of the MDI $(<15 \mathrm{Ncm})$.

The study aims for a number of secondary endpoints including biological and technical complications, chewing efficiency and patient-based outcomes such as satisfaction and quality of life.

The chewing efficiency is measured by a mixing ability test of two-coloured chewing gum, to test the hypothesis that the additional mini-implant support of a toothretained PRDP improves the degree of mixing of the two colours after 20 chewing strokes [36]. For the quantitative evaluation of the flattened and scanned chewing gum specimens, a software was developed for a fast, simple and valid extraction of clinically oriented conclusions [50].

The oral health impact profile (OHIP) is a valid and reliable instrument for the measurement of the oral health related quality of life (OHRQoL) [15, 33]. A significant improvement in the OHRQoL was reported after the placement of standard-diameter implants under existing PRDPs in only one prospective study [15]. Nonetheless, there are some studies that showed some significant increase in patient satisfaction after PRDP stabilization using standard implants $[10,13,14,17]$. In 
another study, distal strategic implants under PRDPs significantly improved the masseter muscle thickness and the maximum bite force [18]. The same research group further reported a particle size reduction after the chewing of silicone test cubes, and a better nutrient intake following the insertion of strategic implants [19]. Many of other studies on strategic standard implants for PRDP stabilization evaluated clinical outcomes exclusively $[6-8,11,12,51-53]$. The 3- to 8-year-survival rates ranged between 90 and $100 \%$ for implants and between 93 and $100 \%$ for PRDPs.

As mentioned previously, a number of studies showed the middle- and long-term behaviour and the positive effect of strategic implants on the performance of PRDPs and patient' satisfaction in recent years. However, some limitations of standard-diameter implants such as high costs, placement effort and treatment duration could be compensated by using mini-implants. Therefore, prospective studies are needed to evaluate the clinical performance and the treatment effect of mini-implants in this indication.

\section{Trial status}

At the time of submission of this paper, the patient recruitment and the implant placement was finished.

\section{Additional file}

Additional file 1: Model consent form given to the participants (In German). (PDF $342 \mathrm{~kb}$ )

\section{Abbreviations \\ BOP, bleeding on probing; ID, identification; MDI, mini dental implant; mod SBI, modified sulcus bleeding index; OHIP-G14, oral health impact profile, Germany, 14 items; OHRQoL, oral health related quality of life; PRDP, partial removable dental prostheses; SPIRIT, standard protocol items, recommendations for interventional trials; $\mathrm{TC}$, treatment coordinator}

\section{Funding}

This study was financially supported by 3 M Deutschland GmbH, Germany. 3 M ESPE has provided the implants and implant materials. The company did not participate in the study design; data assessment and analysis; decision to publish; or in manuscript preparation. $3 \mathrm{M}$ was permitted to review the manuscript, but the final decision on content was retained by the authors.

\section{Availability of data and materials}

The clinical data will not be shared because informed consent was not obtained for publication of the individual patient' dataset.

\section{Authors' contributions}

TM conceived the study and is the treatment coordinator/principal investigator. $\mathrm{AA}$ is the examiner and makes substantial contribution to acquisition of data. TM, AA, RB and FH made substantial contributions to the trial design. CS provided statistical expertise and performed the primary power analyses. BS, JH, CL, FH, and TM perform the treatment of the study participants and revised the study protocol. All authors read and approved the final manuscript.

\section{Authors' information}

TM: Senior lecturer. AA: Assistant professor. BS and JH: Dental practitioners in private practices. CL: Senior lecturer. CS: Mathematician with the focus on medical statistics and epidemiology. RB: Head of the Department of Prosthodontics, Gerodontology and Dental Materials. FH: Dental practitioner in private practice and visiting lecturer of the Department of Prosthodontics, Gerodontology and Dental Materials.

\section{Competing interests}

All authors (except CS) use the implant system in the patient' treatment. TM, $\mathrm{JH}$ and $\mathrm{FH}$ conduct advanced training for dentists by order and for account of the manufacturer 3 M ESPE, Germany. The authors declare that they have no further competing interests.

\section{Consent for publication}

Not applicable.

\section{Ethics approval and consent to participate}

The study protocol and the informed consent form were primarily approved by the Ethics Committee of the University of Greifswald (BB 058/13A) and, secondarily, by the authorized Ethics Committees of the other center (Ethics Committee of the Medical Council Nordrhein No. 2013336, Ethics Committee of the Medical Council Westfalen-Lippe, 2013-406-b-S). Modifications to the protocol, e.g. changes of the study procedures or statistical analysis plan, will require a protocol amendment. Before screening treating dentists or the examiner obtained informed written consent to participate from all patients (Additional file 1).

\section{Author details}

'Department of Prosthodontics, Greifswald University Hospital, Gerodontology and Dental Materials, Greifswald, Germany. ${ }^{2}$ Private Practice, Greifswald, Germany. ${ }^{3}$ Private Practice, Drensteinfurt, Germany. ${ }^{4}$ Department of Oral and Maxillofacial Surgery/Plastic Surgery, Greifswald University Hospital, Greifswald, Germany. ${ }^{5}$ Department of Prosthodontics, Gerodontology and Dental Materials, Private Practice, Morsbach-Lichtenberg, Germany and Greifswald University Hospital, Greifswald, Germany.

Received: 23 February 2016 Accepted: 23 July 2016

Published online: 30 July 2016

\section{References}

1. Muller F, Naharro M, Carlsson GE. What are the prevalence and incidence of tooth loss in the adult and elderly population in Europe? Clin Oral Implants Res. 2007;18 Suppl 3:2-14.

2. Zitzmann NU, Hagmann E, Weiger R. What is the prevalence of various types of prosthetic dental restorations in Europe? Clin Oral Implants Res. 2007;18 Suppl 3:20-33.

3. Mundt T, Polzer I, Samietz S, Grabe HJ, Messerschmidt H, Doren M, et al. Socioeconomic indicators and prosthetic replacement of missing teeth in a working-age population-results of the Study of Health in Pomerania (SHIP). Community Dent Oral Epidemiol. 2009:37:104-15.

4. Szentpetery V, Lautenschlager C, Setz JM. Frictional telescopic crowns in severely reduced dentitions: a 5-year clinical outcome study. Int J Prosthodont. 2012;25:217-20.

5. Mundt T, Polzer I, Samietz S, Grabe HJ, Doren M, Schwarz S, et al. Genderdependent associations between socioeconomic status and tooth loss in working age people in the Study of Health in Pomerania (SHIP). Germany Community Dent Oral Epidemiol. 2011;39:398-408.

6. Kaufmann R, Friedli M, Hug S, Mericske-Stern R. Removable dentures with implant support in strategic positions followed for up to 8 years. Int J Prosthodont. 2009:22:233-41. discussion 42.

7. Joda T. Combined tooth-implant-supported telescopic prostheses in a midterm follow-up of $>2$ years. Int J Prosthodont. 2013;26:536-40.

8. Krennmair G, Krainhofner M, Waldenberger O, Piehslinger E. Dental implants as strategic supplementary abutments for implant-tooth-supported telescopic crown-retained maxillary dentures: a retrospective follow-up study for up to 9 years. Int J Prosthodont. 2007;20:617-22.

9. de Freitas RF, de Carvalho Dias K, da Fonte Porto Carreiro A, Barbosa GA, Ferreira MA. Mandibular implant-supported removable partial denture with distal extension: a systematic review. J Oral Rehabil. 2012;39:791-8.

10. Goncalves TM, Campos CH, Garcia RC. Implant retention and support for distal extension partial removable dental prostheses: satisfaction outcomes. J Prosthet Dent. 2014;112:334-9. 
11. Rinke S, Ziebolz D, Ratka-Kruger P, Frisch E. Clinical Outcome of Double Crown-Retained Mandibular Removable Dentures Supported by a Combination of Residual Teeth and Strategic Implants. J Prosthodont. 2015; 24:358-65.

12. Rammelsberg P, Bernhart G, Lorenzo Bermejo J, Schmitter M, Schwarz S. Prognosis of implants and abutment teeth under combined tooth-implantsupported and solely implant-supported double-crown-retained removable dental prostheses. Clin Oral Implants Res. 2014;25:813-8.

13. Bortolini S, Natali A, Franchi M, Coggiola A, Consolo U. Implant-retained removable partial dentures: an 8-year retrospective study. J Prosthodont. 2011;20:168-72

14. Wismeijer D, Tawse-Smith A, Payne AG. Multicentre prospective evaluation of implant-assisted mandibular bilateral distal extension removable partial dentures: patient satisfaction. Clin Oral Implants Res. 2013;24:20-7.

15. Wolfart S, Moll D, Hilgers RD, Wolfart M, Kern M. Implant placement under existing removable dental prostheses and its effect on oral health-related quality of life. Clin Oral Implants Res. 2013;24:1354-9.

16. Zancope K, Abrao GM, Karam FK, Neves FD. Placement of a distal implant to convert a mandibular removable Kennedy class I to an implant-supported partial removable Class III dental prosthesis: A systematic review. J Prosthet Dent. 2015;113:528-33. e3.

17. Hug S, Mantokoudis D, Mericske-Stern R. Clinical evaluation of 3 overdenture concepts with tooth roots and implants: 2-year results. Int J Prosthodont. 2006;19:236-43.

18. Goncalves TM, Campos CH, Goncalves GM, de Moraes M, Rodrigues Garcia RC. Mastication improvement after partial implant-supported prosthesis use. J Dent Res. 2013;92:189S-94S.

19. Campos CH, Goncalves TM, Rodrigues Garcia RC. Implant retainers for freeend removable partial dentures affect mastication and nutrient intake. Clin Oral Implants Res. 2014;25:957-61.

20. Bidra AS, Almas K. Mini implants for definitive prosthodontic treatment: a systematic review. J Prosthet Dent. 2013;109:156-64.

21. ELsyad MA, Ghoneem NE, El-Sharkawy H. Marginal bone loss around unsplinted mini-implants supporting maxillary overdentures: a preliminary comparative study between partial and full palatal coverage. Quintessence Int. 2013:44:45-52

22. Preoteasa E, Imre M, Preoteasa CT. A 3-year follow-up study of overdentures retained by mini-dental implants. Int J Oral Maxillofac Implants. 2014;29:1170-6.

23. Shatkin TE, Petrotto CA. Mini dental implants: a retrospective analysis of 5640 implants placed over a 12-year period. Compend Contin Educ Dent. 2012;33 Spec 3:2-9.

24. Elsyad MA, Gebreel AA, Fouad MM, Elshoukouki AH. The clinical and radiographic outcome of immediately loaded mini implants supporting a mandibular overdenture. A 3-year prospective study. J Oral Rehabil. 2011:38:827-34

25. Mundt T, Schwahn C, Stark T, Biffar R. Clinical response of edentulous people treated with mini dental implants in nine dental practices. Gerodontology. 2015;32:179-87.

26. Morneburg TR, Proschel PA. Success rates of microimplants in edentulous patients with residual ridge resorption. Int J Oral Maxillofac Implants. 2008;23:270-6.

27. Klein MO, Schiegnitz E, Al-Nawas B. Systematic review on success of narrowdiameter dental implants. Int J Oral Maxillofac Implants. 2014;29(Suppl):43-54.

28. Scepanovic M, Calvo-Guirado JL, Markovic A, Delgardo-Ruiz R, Todorovic A, Milicic B, et al. A 1-year prospective cohort study on mandibular overdentures retained by mini dental implants. Eur J Oral Implantol. 2012;5:367-79.

29. Mundt T, Schwahn C, Biffar R, Heinemann F. Changes in Bone Levels Around Mini-Implants in Edentulous Arches. Int J Oral Maxillofac Implants. 2015;30:1149-55

30. Maryod WH, Ali SM, Shawky AF. Immediate versus early loading of miniimplants supporting mandibular overdentures: a preliminary 3-year clinical outcome report. Int J Prosthodont. 2014;27:553-60.

31. Chan AW, Tetzlaff JM, Gotzsche PC, Altman DG, Mann H, Berlin JA, et al. SPIRIT 2013 explanation and elaboration: guidance for protocols of clinical trials. BMJ. 2013;346, e7586

32. Albrektsson $T$, Zarb G, Worthington $P$, Eriksson AR. The long-term efficacy of currently used dental implants: a review and proposed criteria of success. Int J Oral Maxillofac Implants. 1986;1:11-25.

33. John MT, Miglioretti DL, LeResche L, Koepsell TD, Hujoel P, Micheelis W. German short forms of the Oral Health Impact Profile. Community Dent Oral Epidemiol. 2006;34:277-88.
34. Allen PF, McMillan AS, Walshaw D. A patient-based assessment of implantstabilized and conventional complete dentures. J Prosthet Dent. 2001:85:141-7.

35. Quandt SA, Chen H, Bell RA, Savoca MR, Anderson AM, Leng X, et al. Food avoidance and food modification practices of older rural adults: association with oral health status and implications for service provision. Gerontologist. 2010;50:100-11.

36. Schimmel M, Christou P, Herrmann F, Muller F. A two-colour chewing gum test for masticatory efficiency: development of different assessment methods. J Oral Rehabil. 2007;34:671-8.

37. Elsyad MA, Al-Mahdy YF, Fouad MM. Marginal bone loss adjacent to conventional and immediate loaded two implants supporting a ballretained mandibular overdenture: a 3-year randomized clinical trial. Clin Ora Implants Res. 2012;23:496-503.

38. Gilthorpe MS, Griffiths GS, Maddick $I H$, Zamzuri AT. An application of multilevel modelling to longitudinal periodontal research data. Community Dent Health. 2001;18:79-86.

39. Schaalje GB, McBride JB, Fellingham GW. Adequacy of approximations to distributions of test statistics in complex mixed linear models. J Agric Biol Environ Stat. 2002;7:512-24.

40. Senn S. Seven myths of randomisation in clinical trials. Stat Med. 2013;32:1439-50

41. Kernan WN, Viscoli CM, Makuch RW, Brass LM, Horwitz RI. Stratified randomization for clinical trials. J Clin Epidemiol. 1999:52:19-26.

42. Senn S. Statistical Issues in Drug Development. 2nd ed. Chichester: Wiley; 2007.

43. Harrell Jr FE. Regression Modeling Strategies. With Applications to Linear Models, Logistic and Ordinal Regression, and Survival Analysis. 2nd ed. Heidelberg: Springer; 2015

44. Cook RJ, Farewell VT. Multiplicity considerations in the design and analysis of clinical trials. J R Stat Soc Ser A-Stat Soc. 1996;159:93-110.

45. Rabe-Hesketh S, Skrondal A. Multilevel and Longitudinal Modeling Using Stata. 3rd ed. College Station: Stata Press; 2012.

46. Groenwold RH, Donders AR, Roes KC, Harrell Jr FE, Moons KG. Dealing with missing outcome data in randomized trials and observational studies. Am J Epidemiol. 2012;175:210-7.

47. Wakefield J. Bayesian and Frequentist Regression Methods. New York: Springer; 2013.

48. Gelman A, Hill J. Data Analysis Using Regression and Multilevel/Hierarchical Models. Cambridge: Cambridge University Press; 2007.

49. Walton JN, MacEntee MI. Screening and enrolling subjects in a randomized clinical trial involving implant dentures. Int J Prosthodont. 2008;21:210-4.

50. Halazonetis DJ, Schimmel M, Antonarakis GS, Christou P. Novel software for quantitative evaluation and graphical representation of masticatory efficiency. J Oral Rehabil. 2013:40:329-35.

51. Bernhart G, Koob A, Schmitter M, Gabbert O, Stober T, Rammelsberg P. Clinical success of implant-supported and tooth-implant-supported double crown-retained dentures. Clin Oral Investig. 2012;16:1031-7.

52. Frisch E, Ratka-Kruger $\mathrm{P}$, Wenz HJ. Unsplinted implants and teeth supporting maxillary removable partial dentures retained by telescopic crowns: a retrospective study with $>6$ years of follow-up. Clin Oral Implants Res. 2015;26:1091-7

53. Schwarz S, Bernhart G, Hassel AJ, Rammelsberg P. Survival of double-crownretained dentures either tooth-implant or solely implant-supported: an 8year retrospective study. Clin Implant Dent Relat Res. 2014;16:618-25.

\section{Submit your next manuscript to BioMed Central and we will help you at every step:}

- We accept pre-submission inquiries

- Our selector tool helps you to find the most relevant journal

- We provide round the clock customer support

- Convenient online submission

- Thorough peer review

- Inclusion in PubMed and all major indexing services

- Maximum visibility for your research

Submit your manuscript at www.biomedcentral.com/submit 